\title{
ALTERAÇÕES NO METABOLISMO DO NITROGÊNIO EM PLANTAS DE NONI SOB DUAS CONDIÇÕES HÍDRICAS
}

Dielle Thainá de França Teixeira ${ }^{1}$, Glauco André dos Santos Nogueira ${ }^{2}$, Bruno Moitinho Maltarolo ${ }^{3}$, Wander Luiz da Silva Ataíde $^{3}$, Cândido Ferreira de Oliveira Neto $^{4}$

1 Discente do curso de graduação em Agronomia da Universidade Federal Rural da Amazônia (diellethaina@hotmail.com) Belém-Brasil

2 Discente de doutorado no programa de Ciências Florestais da Universidade Federal Rural Amazônia

3 Discente de mestrado no programa de Ciências Florestais da Universidade Federal Rural Amazônia

4 Engenheiro Agrônomo, Professor Doutor do Instituto de Ciências Agrárias da Universidade Federal Rural da Amazônia

Recebido em: 08/09/2015 - Aprovado em: 14/11/2015 - Publicado em: 01/12/2015 DOI: http://dx.doi.org/10.18677/Enciclopedia_Biosfera_2015_073

O objetivo da pesquisa foi avaliar respostas de compostos nitrogenados em relação ao conteúdo relativo de água em plantas de noni (Morinda citrifolia L.) submetidas à deficiência hídrica em um intervalo de 10 dias. O experimento foi conduzido em casa de vegetação da Universidade Federal Rural da Amazônia no Campus de Capitão Poço/PA. Foi utilizado o delineamento inteiramente casualizado com dois regimes hídricos (controle; deficiência hídrica) com 16 repetições. Foi aplicada a análise de variância nos resultados e comparadas às médias pelo teste de Tukey ao nível de $5 \%$ de significância. O conteúdo relativo de água diminuiu nas plantas sob deficiência hídrica. Essa falta de água proporcionou reduções significativas nas concentrações de nitrato nas raízes de 0,74 para 0,13 umoles de $\mathrm{NO}_{3}{ }^{-} / \mathrm{g}$ MS e nas folhas de 0,42 para $0,07 \mu$ moles de $\mathrm{NO}_{3}^{-} / \mathrm{g}$ MS para as plantas controle e sob deficiência hídrica, respectivamente. A deficiência hídrica também promoveu decréscimo na atividade da redutase do nitrato em raízes e folhas, o mesmo não ocorrendo com as concentrações de amônio livre onde obtiveram um incremento nas raízes de 13,7 para 18,5 de mmol de $\mathrm{NH}_{4}{ }^{+} / \mathrm{Kg}$ MS e nas folhas 4,3 para 8,6 mmol de $\mathrm{NH}_{4}^{+} / \mathrm{Kg}$ MS para as plantas controle e deficiência hídrica, respectivamente. As concentrações de aminoácidos solúveis totais e prolina aumentaram nas raízes e folhas. No caso das concentrações de proteínas solúveis totais houve diminuição tanto nas raízes como nas folhas. As condições de estresse hídrico promoveram alterações nos parâmetros bioquímicos nas folhas e raízes de noni.

PALAVRAS-CHAVE: Compostos nitrogenados; Deficiência hídrica; Parâmetros bioquímicos. 


\title{
CHANGES IN THE NITROGEN COMPOUNDS IN PLANTS OF NONI UNDER TWO WATER CONDITIONS
}

\begin{abstract}
The objective of the research was to evaluate responses of nitrogen compounds in relation to the relative water content in noni plant (Morinda citrifolia L.) submitted to water deficit in an interval of 10 days. The experiment was conducted on a greenhouse of the Universidade Federal Rural da Amazônia, Capitão Poço/PA Campus. We used a completely randomized design with two water treatments (control, water deficit) with 16 repetitions. Analysis of variance was applied to the results and compared the means by Tukey test at $5 \%$ significance level. The relative water content decreased in plants under water stress. This lack of water provided significant reductions in nitrate concentrations in the roots of 0,74 to $0,13 \mu$ moles of $\mathrm{NO}_{3}{ }^{-} / \mathrm{g}$.DM and leaves of 0,42 to $0,07 \mu$ moles of $\mathrm{NO}_{3} / \mathrm{g} \mathrm{DM}$ for control and under water deficit plants, respectively. Water deficit also promoted decrease in nitrate reductase activity in leaves and roots, which did not occur with the free ammonium concentrations where they obtained an increase in the roots of 13,7 to $18,5 \mathrm{mmol}$ of $\mathrm{NH}_{4}{ }^{+} / \mathrm{Kg} \mathrm{DM}$ and the leaves 4.3 to $8.6 \mathrm{mmol}$ of $\mathrm{NH}_{4}{ }^{+} / \mathrm{Kg} \mathrm{DM}$ for the control plants and water deficit, respectively. The total soluble amino acid and proline concentrations increased in roots and leaves. In the case of total soluble protein concentration decreased both roots and leaves. The water stress promoted changes in biochemical parameters in leaves and roots of noni.
\end{abstract}

KEYWORDS: Biochemical parameters; Nitrogen compounds; Water deficit.

\section{INTRODUÇÃO}

Apesar da planta de noni (Morinda citrifolia L.) ser explorada no continente asiático por mais de 2000 anos, no Brasil o seu fruto é praticamente desconhecido, o seu processo de entrada no país ocorreu há poucos anos, contudo não há material propagativo suficiente para ser cultivado comercialmente, porém, nos últimos anos, tem se observado um aumento significativo do interesse comercial em relação aos produtos contendo essa planta, principalmente o suco da fruta do noni (SILVA et al., 2012).

A seca é um fator que abrange as plantas em vários níveis de organização, desde nível celular e órgãos até a planta inteira (LAMBERS et al., 2008). O déficit hídrico causado pela seca induz diferentes respostas bioquímicas e fisiológicas nas plantas, representando o fator ambiental que mais influencia o crescimento e produção, em escala mundial (NEMANI et al., 2003). Contudo, tem sido fundamental o aprofundamento de pesquisas cientificas no âmbito fisiológico para que se elaborem fichas de descritores fisiológicos que classifiquem as espécies em tolerantes e adaptadas aos diversos fatores de estresses ambientais.

Pesquisas confirmam que os solutos orgânicos protegem as plantas dos estresses por meio de diferentes mecanismos, incluindo ajustamento osmótico, remoção das espécies ativas de oxigênio, "proteção da integridade das membranas celulares" e estabilização de proteínas e enzimas (POMPELLI et al., 2010). O metabolismo nitrogenado também é sensivelmente afetado pela falta de água, sendo que o processo de produção de proteína é um dos primeiros eventos metabólicos paralisados após a percepção do estresse hídrico (MARAGHNI et al., 2011). TURKAN (2011) afirma que após o fechamento estomático, plantas sob estresse moderado iniciam a proteólise, promovendo um aumento no conteúdo de 
aminoácidos livres, com consequente diminuição da concentração de proteínas.

Um dos principais aminoácidos que são formados em virtude de ajustamento osmótico é a prolina, e isso é ratificado por CVIKROVÁ et al., (2013); FILIPPOU et al., (2014) quando afirmam que o aumento nos teores de prolina minimiza os efeitos do estresse hídrico. Segundo os mesmos autores, o acúmulo ocorre pela síntese "de novo" ou pela inibição do processo de oxidação da prolina (SZÁBADOS et al., 2011). A falta de água no solo também afeta a síntese de proteínas, a atividade de algumas enzimas, como a nitrato redutase (SALISBURY \& ROSS, 2012). Diante do exposto, objetivou-se avaliar as alterações do metabolismo do nitrogênio em plantas jovens de noni submetidas à deficiência hídrica.

\section{MATERIAL E MÉTODOS}

\section{Local do experimento}

O experimento foi conduzido em casa de vegetação da Universidade Federal Rural da Amazônia (UFRA), Campus de Capitão Poço, no município de Capitão Poço localizada na microrregião do Guamá no Estado do Pará, com latitude de 0141"36' S e longitude 04706"39' W e altitude méd ia da área em torno de $73 \mathrm{~m}$. O clima da região, segundo a classificação de Köppen, é do tipo Am com precipitação anual em torno de $2.500 \mathrm{~mm}$, com uma curta estação seca entre setembro e novembro (precipitação mensal em torno de $60 \mathrm{~mm}$ ), temperatura média de $26^{\circ} \mathrm{C} \mathrm{e}$ umidade relativa do ar entre $75 \%$ e $89 \%$ nos meses com menor e maior precipitação, respectivamente (SCHWART, 2007).

\section{Amostragem}

Foram utilizadas mudas de noni e colocadas por um mês em aclimatação. $O$ experimento foi feito no mês de maio de 2010, no qual a simulação da deficiência hídrica foi no período de 10 dias. O manejo da irrigação foi realizado de forma manual, o solo da planta controle era sempre mantido na capacidade de campo.

O delineamento experimental utilizado foi inteiramente casualizado com dois regimes hídricos (duas condições hídricas: controle, com irrigação diária, e deficiência hídrica), com 16 repetições, totalizando 32 unidades experimentais, cada unidade experimental foi composta de uma planta/vaso. Foi aplicada a análise de variância nos resultados e comparadas às médias pelo teste de Tukey ao nível de 5\% de significância, realizadas por meio do SAS-INSTITUTE (1996).

\section{Conteúdo relativo de água}

Analisou-se nas folhas o conteúdo relativo de água, o qual foi obtido utilizando o método descrito por SLAVICK (1974), sendo retirados 30 discos foliares $(10 \mathrm{~mm}$ de diâmetro) de cada planta, ao acaso, determinando imediatamente a massa dos mesmos (MF1) em balança analítica. Os discos pesados foram transferidos para uma placa de Petri contendo $35 \mathrm{~mL}$ de água destilada e deixados na bancada (25 C) por um período de 6-7 horas. Após, os discos fo ram colocados em papel de filtro para retirar o excesso de água (1 $\mathrm{min})$ e, em seguida, pesados para determinar a massa túrgida (MF2). Depois, os discos foram colocados em saco de papel, levados à estufa $\left(75^{\circ} \mathrm{C}\right)$ por $48 \mathrm{~h}$ e, posteriormente, foi de terminada a massa seca dos discos (MS). 


\section{Concentrações de nitrato}

Foram pesados $50 \mathrm{mg}$ das folhas previamente liofilizadas, e adicionadas em tubos de ensaio contendo $5,0 \mathrm{~mL}$ de água destilada, e estes incubados em banhomaria por 30 minutos a $100{ }^{\circ} \mathrm{C}$. Em seguida, este quantitativo foi centrifugado a 3.000 rpm por 10 minutos e retirado o sobrenadante. A reação foi preparada em tubo de ensaio contendo $100 \mu \mathrm{L}$ do extrato $+200 \mu \mathrm{L}$ de solução de ácido salicílico $5 \%$ $(\mathrm{p} / \mathrm{v})$, em ácido sulfúrico concentrado. Após vigorosa agitação em agitador do tipo vortex, adicionaram-se lentamente $4700 \mu \mathrm{L}$ de $\mathrm{NaOH} 2 \mathrm{~N}$. Em seguida, os tubos foram deixados em repouso até atingirem a temperatura ambiente por cerca de 20 minutos. Após este processo, foram feitas leituras em espectrofotômetro na absorbância de $410 \mathrm{~nm}$. O branco foi feito usando no ensaio água deionizada em substituição ao extrato. A concentração de nitrato foi obtida a partir de uma curva padrão com concentrações crescentes de $\mathrm{NO}_{3}{ }^{-}(0,0,5,1,0,2,0,3,0,4,0$ e $5,0 \mu \mathrm{mol}$ $\mathrm{mL}^{-1}$ ). Os resultados foram expressos em mmol de $\mathrm{NO}_{3}{ }^{-} \cdot \mathrm{kg}^{-1} \mathrm{MS}$ de tecido. $\mathrm{O}$ método utilizado foi o de CATALDO et al., (1975).

\section{Atividade da redutase do nitrato}

Foram retirados e pesados aproximadamente $200 \mathrm{mg}$ de discos de $0,5 \mathrm{~cm}$ de diâmetro das folhas. Logo após as amostras foram colocadas em tubos de ensaio, contendo $5 \mathrm{~mL}$ do tampão fosfato $0,1 \mathrm{M}, \mathrm{pH} 7,5$; contendo isopropanol $1 \%(\mathrm{v} / \mathrm{v})$, $\mathrm{KNO}_{3} \mathrm{mM}$ ) e estes cobertos com papel alumínio (tratamento escuro). Em seguida, os tubos foram evacuados com o auxílio de uma bomba de vácuo, durante dois minutos. Por seguinte, os tubos foram colocados em "banho-maria" a $30 \stackrel{\circ}{ } \mathrm{C}$, por 30 minutos, na ausência de luz. Em tubos de ensaio tipo pirex, foram adicionados alíquotas de $1 \mathrm{~mL}$ de tampão fosfato $+2 \mathrm{~mL}$ do extrato diluído $+1,0 \mathrm{~mL}$ de sulfanilamida $1 \%+1,0 \mathrm{~mL}$ de $\mathrm{N}$-1-naftiletilenodiamina dicloridrato (NNEDA) $0,02 \%$, totalizando um volume final de $5 \mathrm{~mL}$. Em seguida, os tubos foram deixados em repouso por 15 minutos. A leitura foi no espectrofotômetro a $540 \mathrm{~nm}$ contra o branco (3,0 mL de tampão fosfato $+1,0 \mathrm{~mL}$ de sulfanilamida $1 \%+1,0 \mathrm{~mL}$ de NNEDA, 0,02 $\%)$. O resultado da atividade da redutase do nitrato foi estimado através da produção de $\mathrm{NO}_{2}^{-}$no meio de reação, sendo expressa em $\mu$ moles de $\mathrm{NO}_{2}^{-} \cdot \mathrm{g} \mathrm{MF}^{-1} \cdot \mathrm{h}^{-1}$, a partir de uma curva-padrão obtida com $\mathrm{KNO}_{2}$ p.a (Sigma). O método empregado foi o método in vivo preconizado por HAGEMAN \& HUCKLESBY (1949).

\section{Concentrações de amônio livre}

Foram pesados $50 \mathrm{mg}$ de massa seca (MS) das folhas em pó, e colocados em tubos de ensaio de $15 \mathrm{~mL}$, adicionando-se $5 \mathrm{~mL}$ de água destilada e levados ao banho-maria por 30 min a $100^{\circ} \mathrm{C}$. Após a extração as amostras foram centrifugadas em centrífuga de bancada a $1000 \mathrm{rpm}$ e os sobrenadantes coletados para obtenção do extrato total. Nos tubos de ensaio foram acrescentados $400 \mu \mathrm{L}$ de extrato total + $2,5 \mathrm{~mL}$ da solução $\mathrm{A}$ ( $5 \mathrm{~g}$ de fenol $+0,025 \mathrm{~g}$ de nitroprussiato de sódio/ $500 \mathrm{~mL}$ de água destilada) e homogeneizado em vortex, acrescentando $2,5 \mathrm{~mL}$ da solução $B$ (2,5 g de NaOH $+12,6 \mathrm{~mL}$ de hipoclorito de sódio/ $500 \mathrm{~mL}$ de água destilada) e foram agitados novamente em vortex, levando-os ao banho-maria por 20 min a 37 ${ }^{\circ} \mathrm{C}$. Após esse período foram removidos do "banho-maria" e deixados em repouso por $40 \mathrm{~min}$, em seguida, levados para fazer a leitura no espectrofotômetro a $625 \mathrm{~nm}$ e usando-se água destilada (em substituição ao extrato) + reagentes como branco. As concentrações de amônio livre foram estimadas a partir da curva-padrão construída com $\left(\mathrm{NH}_{4}\right)_{2} \mathrm{SO}_{4}$ p.a (Sigma). Os resultados foram expressos em mmol de ENCICLOPÉDIA BIOSFERA, Centro Científico Conhecer - Goiânia, v.11 n.22; p.92 2015 
$\mathrm{NH}_{4}{ }^{+} / \mathrm{kg}$ MS. Para isso, utilizou-se o método descrito por (WEATHERBURN, 1967).

\section{Concentrações de aminoácidos solúveis totais}

Foram pesados $50 \mathrm{mg}$ das folhas e das raízes, e colocados em tubos de ensaio com $5 \mathrm{~mL}$ de água deionizada, fechados hermeticamente e incubados em banho-maria a $100{ }^{\circ} \mathrm{C}$, durante 30 minutos. Em seguida, os tubos foram centrifugados a $6.000 \times \mathrm{g}$, por 10 minutos. Após a extração o sobrenadante foi coletado e desenvolvido a reação para dosagem dos aminoácidos. Alíquotas de 0,1 $\mathrm{mL}$ do extrato foram colocadas em tubos de ensaio e acrescidas de $0,4 \mathrm{~mL}$ de água mille-Q. Em seguida $0,250 \mathrm{~mL}$ de uma solução tamponada, $\mathrm{pH} 5,0$, contendo 0.2 mol. $\mathrm{L}^{-1}$ de citrato; $0,250 \mathrm{~mL}$ do reagente de ninhidrina (KCN 0,1 mmol. $\mathrm{L}^{-1}$ e ninhidrina $5 \%$ em methoxy etanol) foi adicionado. Após misturar bem em vortex os tubos foram hermeticamente fechados e colocados em "banho-maria", no qual permaneceram pelo tempo de 15 minutos à temperatura de $100^{\circ} \mathrm{C}$. E m seguida, a reação foi interrompida em banho de gelo, momento em que foram adicionados $1,5 \mathrm{~mL}$ de uma solução de etanol $50 \%(\mathrm{v} / \mathrm{v})$. Após os tubos permanecerem por 20 minutos em temperatura ambiente, foram efetivadas leituras em espectrofotômetro, a $570 \mathrm{~nm}$, sendo os teores de aminoácidos livres totais, determinado com base em uma curva padrão ajustada a partir de concentrações crescentes de uma mistura padronizada de L-glutamina. A concentração de aminoácidos livres totais (AALT) foi determinada segundo método descrito por PEOPLES et al., (1989).

\section{Concentrações de proteínas solúveis totais}

Foram colocados em tubos de ensaio de $15 \mathrm{~mL} 100 \mathrm{mg}$ de pó da matéria seca das raízes e das folhas em 5,0 mL do tampão de extração (Tris-HCl $25 \mathrm{mM} \mathrm{pH} \mathrm{7,6).}$ Em seguida os tubos, devidamente lacrados, ficaram sob agitação durante duas horas no "shacker". Após esse processo, os tubos foram centrifugados em centrífuga de bancada (2000 rpm por 10 minutos). Em seguida, foram colocados nos tubos de ensaios $100 \mathrm{~mL}$ do sobrenadante após a centrifugação $+2,5 \mathrm{~mL}$ do reagente de Bradford. Após este processo os tubos manualmente foram agitados delicadamente (para não desnaturar as proteínas). Com $15 \mathrm{~min}$ de repouso as leituras foram realizadas no espectrofotômetro a $595 \mathrm{~nm}$, contra o branco que encerra $100 \mathrm{~mL}$ de água $+2,5 \mathrm{~mL}$ do reagente de Bradford. As concentrações de proteínas solúveis totais foram estimadas a partir da curva-padrão construída com soro albumina bovina p.a (Sigma). Os resultados foram expressos em $\mathrm{mg}$ proteína/ g MS. As concentrações de proteínas solúveis totais foram determinadas segundo o método de BRADFORD, (1976).

\section{Concentrações de Prolina}

Os teores de prolina, a extração foi realizada a quente (em banho-maria a 100 ${ }^{\circ} \mathrm{C}$, por $30 \mathrm{~min}$ ), homogeneizando-se as amostras em c inco $\mathrm{mL}$ de água destilada. Após centrifugação a $700 \mathrm{~g}$, por $20 \mathrm{~min}$, o sobrenadante foi coletado e deste utilizado uma alíquota de um $\mathrm{mL}$ para a quantificação de prolina, iniciada pela adição de um $\mathrm{mL}$ de ninhidrina ácida e um $\mathrm{mL}$ de ácido acético glacial 99,5\%. A mistura foi agitada e incubada a $100^{\circ} \mathrm{C}$ por uma hora. As amostr as foram resfriadas em banho de gelo e a elas adicionadas dois $\mathrm{mL}$ de tolueno para a separação das fases. A fração contendo grupo cromóforo foi coletada e a absorvância (ABS) determinada a $520 \mathrm{~nm}$ em espectrofotômetro UV-Visível (mod. GenesysTM 10series, Marca Thermo Electron Corporation, Wisconsin, USA). A concentração de prolina foi ENCICLOPÉDIA BIOSFERA, Centro Científico Conhecer - Goiânia, v.11 n.22; p.93 
determinada por meio de curva de calibração de prolina e o resultado expresso em $\mathrm{mmoL}$ prolina $\mathrm{g}^{-1}$ de matéria seca (MS). Foram determinados de acordo com BATES et al., (1973).

\section{Conteúdo relativo de água}

\section{RESULTADOS E DISCUSSÃO}

Os resultados mostraram que as plantas de noni sob suspensão hídrica de 10 dias tiveram uma diminuição significativa de $89 \%$ para 59\% no conteúdo relativo de água. Essa diminuição é devida à falta de água no solo e pela retenção de moléculas de água no coloide não permitindo a liberação dessa água para o uso na planta. Segundo COOPER et al., (2012), essa retenção pode estar relacionada à maior densidade e ao maior conteúdo de argila, que resulta em uma grande proporção de microporos e por conseguinte, maior retenção de água. Conforme a quantidade de água no solo diminui, a sucção do solo aumenta e a absorção de água pelas raízes dificulta, até que, no ponto de murcha permanente, a sucção do solo excede a sucção que pode ser exercida pela planta, e a absorção tende a cessar. Contudo, estudos (CHA-UM et al., 2010; PAIXÃO et al., 2014) mostram que mesmo quando se alcança um ponto baixo de umidade no solo, uma quantidade pequena de água permanece a entrar na planta, porém não é suficiente para manter o crescimento.

Resultados semelhantes foram obtidos por PACHECO et al., (2011), ao avaliarem a deficiência hídrica em calêndula quando observaram uma diminuição significativa, atingindo o valor médio de $48,5 \%$.

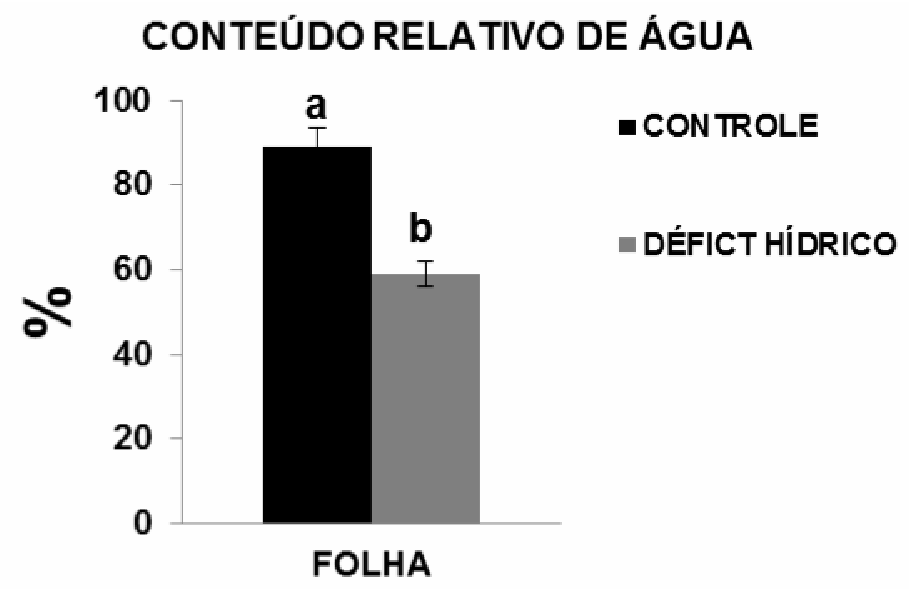

FIGURA 1 Conteúdo relativo de água folhas de plantas jovens de noni (Morinda citrifolia) submetidas à deficiência hídrica durante 10 dias. As letras diferentes mostram diferença estatística, comparadas pelo teste Tukey ao nível de $5 \%$ de probabilidade. As barras representam os desvios padrões das médias.

\section{Concentrações de nitrato}

A redução do conteúdo relativo de água (Figura 1) promoveu um decréscimo de nitrato da raiz de 0,74 para $0,13 \mu$ moles de $\mathrm{NO}_{3}^{-} / \mathrm{g}$ MS e nas folhas de 0,42 para 0,07 umoles de $\mathrm{NO}_{3}{ }^{-} / \mathrm{g}$ MS para as plantas controle e sob deficiência hídrica, correspondendo a um decréscimo de $82,43 \%$ e $83,33 \%$ respectivamente (Figura 2). 
A redução de nitrato é resultado do baixo fluxo da corrente transpiratória na planta, esta vai ajudar o transporte de nutrientes, refletindo com isso na baixa atividade da enzima redutase do nitrato (Figura 3) nas raízes e folhas, tendo em vista que a enzima depende do fornecimento de nitrato da raiz para a folha. De acordo com ANDRADE NETO (2005) a atividade da enzima redutase do nitrato não chegou a reduzir totalmente a atividade em razão do fornecimento constante embora reduzido, de nitrato oriundo da reserva do vacúolo das células, como pôde ser observado neste trabalho. Além disso, a redução da disponibilidade do íon nitrato para as plantas pode inibir a transcrição do gene da enzima redutase do nitrato, bem como a estabilidade dos mRNAs desta enzima (SHARMA \& DUBEY, 2005).

O nitrato é absorvido pelas raízes e pode então ser reduzido ou armazenado nos vacúolos, ou translocados para a parte aérea, onde será reduzido ou armazenado nos vacúolos foliares. Primeiramente a redução ocorre no citosol e envolve a ação da enzima redutase do nitrato $(R N)$, produzindo nitrito, este adentra os plastídeos, cloroplastos em folhas sendo reduzido a amônio por ação da enzima redutase do nitrito (NiR), esta é fixada via GS/GOGAT em aminoácidos, glutamina e glutamato, que por sua vez servem de substrato para reações de trasaminação, para a produção de todos os outros aminoácidos necessários à síntese de proteínas (CAMARGOS, 2002).

Resultados semelhantes foram encontrados por MELO (2008) ao trabalharem com café sob deficiência hídrica, verificando uma diminuição do fluxo de nitrato em decorrência da falta de umidade no solo, onde o íon funciona como principal fator regulador da enzima redutase do nitrato, causando deste modo um decréscimo na atividade da enzima.

\section{CONCENTRAÇÕES DE NITRATO}

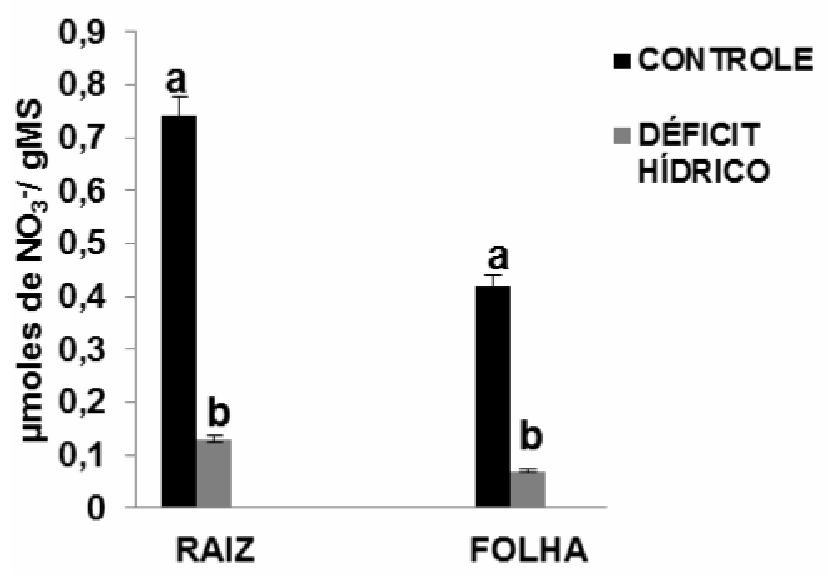

FIGURA 2 Concentrações de nitrato em raízes e folhas de plantas jovens de noni (Morinda citrifolia) submetidas à deficiência hídrica durante 10 dias. As letras diferentes mostram diferença estatística, comparadas pelo teste Tukey ao nível de $5 \%$ de probabilidade. As barras representam os desvios padrões das médias. 


\section{Atividade da redutase do nitrato}

As plantas controle apresentaram atividade de 0,12 $\mu$ moles de $\mathrm{NO}_{2}{ }^{-} / \mathrm{h} . \mathrm{g} \mathrm{MF}$ nas raízes e 0,08 $\mu$ moles de $\mathrm{NO}_{2}^{-} / \mathrm{h} . \mathrm{g}$ MF nas folhas. Após 10 dias de deficiência hídrica, as plantas de noni tiveram decréscimo da atividade da redutase $(R N)$ do nitrato de $84,16 \%$ nas raízes e $92,5 \%$ nas folhas (Figura 3 ).

A diminuição do fluxo de água pela corrente transpiratória diminuiu também a entrada de nitrato na planta e o fluxo para as folhas. Essa diminuição do nitrato provavelmente causou a redução da atividade da RN em virtude dessa enzima ser altamente dependente do substrato. Estudos feitos por SILVA et al., (2011) e SANTOS, et al., (2012) comprovaram essa dependência do substrato (nitrato).

Outro fator que contribui muito para a redução da atividade da RN é a baixa concentração de $\mathrm{CO}_{2}$ (KAISER \& HUBER, 2001), quando as plantas se encontram em deficiência hídrica, uma das muitas reações fisiológicas adotadas pela planta para diminuir a perda d'água, trata-se do fechamento estomático. O fechamento estomático acaba impedindo, ou pelo menos dificultando, as trocas gasosas. ANDRADE-NETTO, (2005) trabalhando com sombreamento em Caffea Arabica relacionou a diminuição da atividade da $\mathrm{RN}$ ao fechamento dos estômatos.

Esta enzima $(\mathrm{RN})$ citosólica é de extrema importância para o metabolismo vegetal, apesar da baixíssima atividade enzimática $(R N)$ nas mudas de noni sob deficiência hídrica. É importante ressaltar que foi possível perceber alguma atividade da $\mathrm{RN}$ e provavelmente, essa baixa atividade foi devido à presença constante do nitrato $\left(\mathrm{NO}_{3}^{-}\right)$, vindo da reserva do vacúolo.

Os resultados encontrados na atividade da $\mathrm{RN}$ em planta de Noni corroboram com ALVES et al., (2012) que observaram a diminuição da atividade da RN em plantas de Tabebuia serratifolia quando submetidas a estresse hídrico. Outra espécie que também diminuiu a RN sob deficiência hídrica foi o milho (SOUZA et al., 2014). O noni apresenta atividade de $R N$ tanto nas folhas quanto nas raízes, sendo mais elevado nas raízes como também é o caso do Cuminum Cyminum L. (SEPEHR et al., 2012). O inverso acontece com a espécie açaí (SANTOS, et al., 2012) onde a atividade da RN é maior nas folhas do que nas raízes em condições normais.

\section{ATIVIDADE DA REDUTASE DO NITRATO}

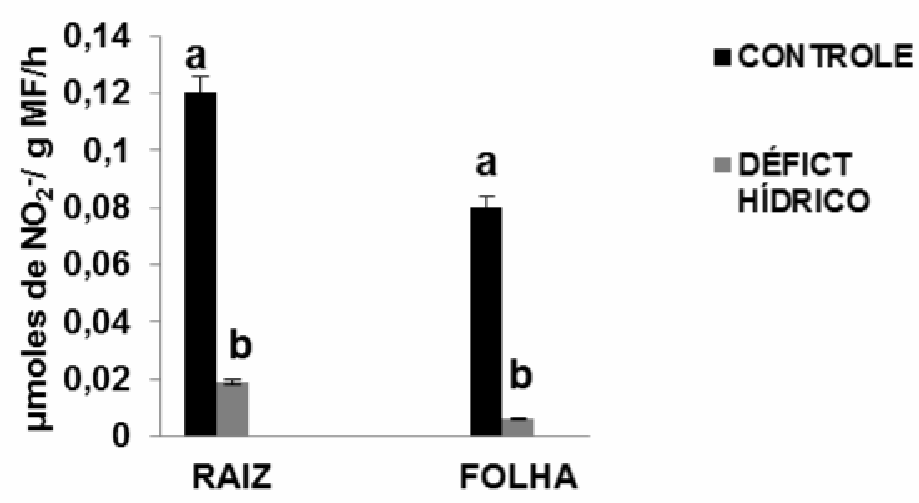

FIGURA 3 Atividade da redutase do nitrato em raízes e folhas de plantas jovens de noni (Morinda citrifolia) submetidas a deficiência hídrica durante 10 dias. As letras diferentes mostram diferença estatística, comparada pelo teste Tukey ao nível de $5 \%$ de probabilidade. As barras representam os desvios padrões das médias. 


\section{Amônio livre}

As concentrações de amônio tiveram um incremento nas raízes de 13,7 para 18,5 de mmol de $\mathrm{NH}_{4}{ }^{+} / \mathrm{Kg}$ MS e nas folhas de 4,3 para 8,6 mmol de $\mathrm{NH}_{4}{ }^{+} / \mathrm{Kg} \mathrm{MS}$ para as plantas controle e sob deficiência hídrica, correspondendo a $74 \%$ e $50 \%$ respectivamente (Figura 4). Esses resultados provavelmente possam ser explicados pela redução da atividade de glutamina sintetase. Apesar dessa enzima possuir substrato (amônio) suficiente para a ativação desta enzima, a falta de energia (ATP) e a redução de glutamato no meio celular, através da possível diminuição da taxa fotossintética e do metabolismo dos aminoácidos, são essenciais para manter a atividade desta enzima (OLIVEIRA NETO, 2008).

A assimilação do nitrogênio é afetada pelo déficit hídrico, sendo observadas reduções drásticas na atividade da enzima redutase do nitrato, a partir de pequenos decréscimos no potencial hídrico nos macro e microporos do solo (BOTREL et al., 2000). É neste contexto que as enzimas envolvidas na incorporação de amônio a compostos orgânicos, os quais podem agir como precursores para diferentes metabólitos podem ter importante papel na sobrevivência de plantas durante esse tipo de estresse (FERREIRA et al., 2002).

De acordo com CARVALHO (2012) é importante frisar que a pequena quantidade de amônio transportada via xilema para as folhas, não foi responsável pela provável alta atividade de glutamina sintetase encontrada em seringueira (Hevea sp), o que leva a inferir a mesma ideia também para o noni empregado neste estudo.

Resultado este que se mostrou inverso aos resultados obtidos neste estudo. CRUZ (2001) avaliando a influência de amônio e nitrato sobre a concentração de compostos nitrogenados em mandioca verificou que nas raízes e folhas de plantas cultivadas apenas com amônio apresentaram os mais elevados teores de aminoácidos, afirmando a ideia de que a redução do nitrato leva ao aumento da atividade da GS (glutamina sintetase) e GOGAT (glutamato sintase), enzima responsável pela assimilação do amônio e formação de aminoácidos.

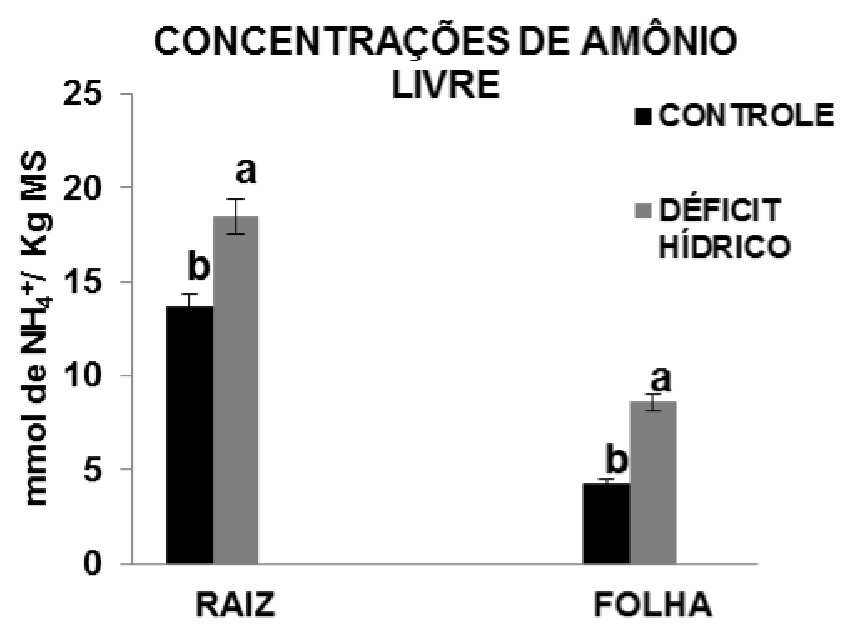

FIGURA 4 Concentrações de amônio livre em raízes e folhas de plantas jovens de noni (Morinda citrifolia) submetidas à deficiência hídrica durante 10 dias. As letras diferentes mostram diferença estatística, comparadas pelo teste Tukey ao nível de $5 \%$ de probabilidade. As barras representam os desvios padrões das médias. 


\section{Concentrações de aminoácidos solúveis totais}

As concentrações de aminoácidos solúveis totais tiveram um acréscimo nas raízes de 13,6 para 59,9 de $\mu \mathrm{mol}$ de AA/g MS e nas folhas 19,3 para 74,6 $\mu \mathrm{mol}$ de AA/g MS para as plantas controle e sob deficiência hídrica respectivamente (figura 5). O acréscimo de aminoácido nas raízes das plantas sob deficiência hídrica foi de $340 \%$ e nas folhas $287 \%$. Esse estresse interfere basicamente no metabolismo bioquímico da planta e como uma forma de defesa contra falta de água, a planta muda o comportamento metabólico como, por exemplo, a degradação das proteínas em aminoácidos, dentre desses a prolina (figura 7) que está diretamente ligada ao ajustamento osmótico do tecido foliar das células (SOUZA et al., 2014).

Outra resposta dos vegetais à deficiência hídrica inclui alterações bioquímicas em nível celular, como exemplo as peroxidases, mudanças nas proporções de aminoácidos e aumentos frequentes na concentração de prolina são ocasionados por distúrbios no metabolismo das proteinases, possivelmente para manutenção do potencial hídrico da folha, que aumenta o teor deste aminoácido, para ajuste osmótico e defesa da planta à desidratação (SOUSA et al., 2015).

O acúmulo de aminoácidos pode ser decorrente de distúrbios provocados pela deficiência hídrica nos tecidos do floema, reduzindo a translocação para outros órgãos. Aumento do aminoácido sob deficiência hídrica foi encontrado também por OLIVEIRA et al., (2013) em plantas jovens de graviola e por SILVA et al., (2010) em Coffea canéfora.

CONCENTRAÇÕES DE AMINOÁCIDOS LIVRES TOTAIS

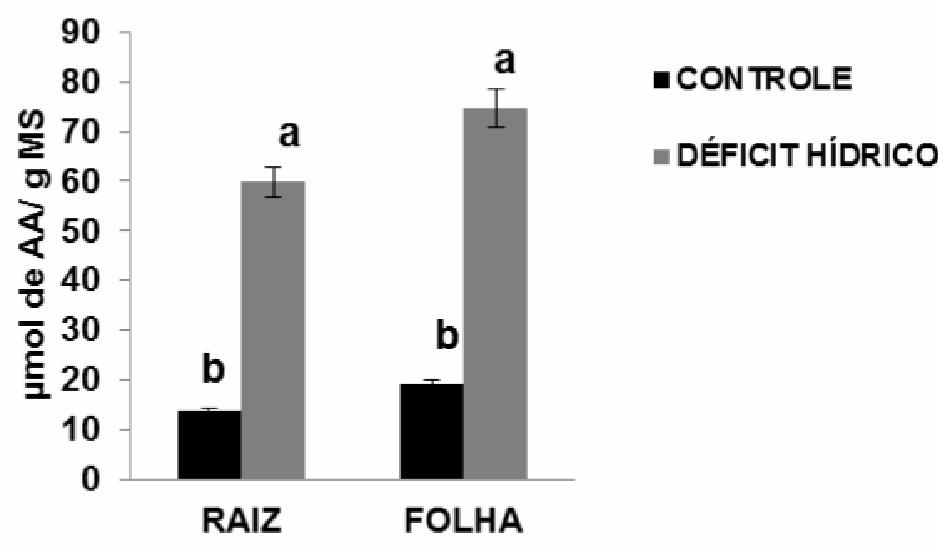

FIGURA 5 Concentrações de aminoácidos livres totais $\mathrm{s}$ solúveis totais nas raízes e folhas de plantas jovens de noni (Morinda citrifolia) submetidas à deficiência hídrica durante 10 dias. As letras diferentes mostram diferença estatística, comparada pelo teste Tukey ao nível de $5 \%$ de probabilidade. As barras representam os desvios padrões das médias. 


\section{Concentrações de proteínas solúveis totais}

As concentrações de proteínas solúveis totais da raiz, onde os valores encontrados quando comparado as plantas controle foram de 2,21 para 0,63 mg de Proteína/g MS representando uma diminuição de $71,49 \%$. Os resultados para as folhas foram de 3,32 para 1,67 mg de Proteína/ $\mathrm{g}$ MS representado uma queda de $49,69 \%$ (Figura 6). Esse resultado evidencia que quanto mais baixo o potencial hídrico do solo, maior a atividade das enzimas proteolíticas que são responsáveis pela degradação das proteínas de reserva das plantas, diminuindo os teores destas nas folhas, além da redução da síntese "de novo" das mesmas durante a falta de água (FREITAS, 2014).

Estudos desenvolvidos por PAULA et al., (2013), encontraram valores das médias das plantas analisadas no período seco uma redução nos teores de proteínas solúveis totais de $34 \%$ em comparação com as plantas analisadas no período chuvoso. Possivelmente, esse tipo de estresse interfere basicamente no metabolismo bioquímico da planta e como uma forma de defesa contra falta de água, a planta muda o comportamento metabólico.

\section{CONCENTRAÇÕES DE PROTEINAS SOLÚVEIS TOTAIS}

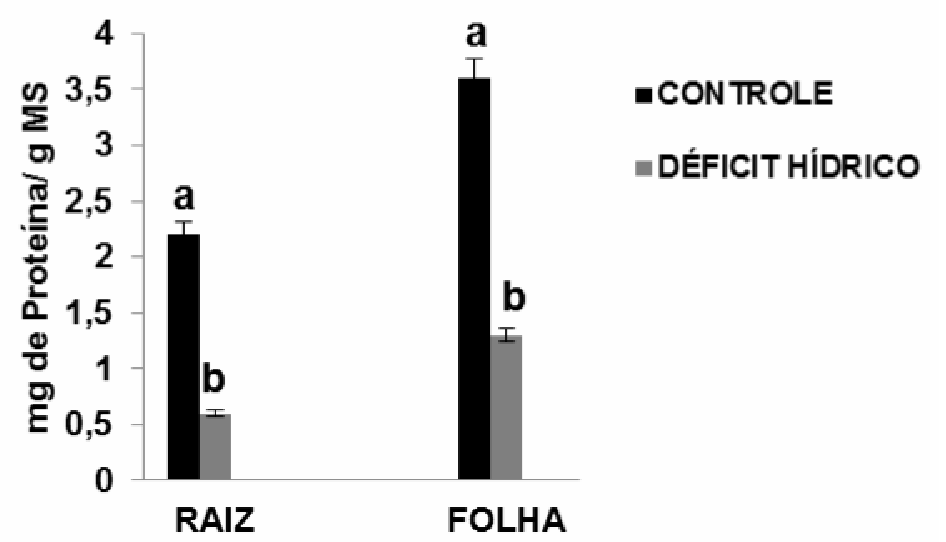

FIGURA 6 Concentrações de proteínas solúveis totais nas raízes e folhas de plantas jovens de noni (Morinda citrifolia) submetidas à deficiência hídrica durante 10 dias. As letras diferentes mostram diferença estatística, comparadas pelo teste Tukey ao nível de $5 \%$ de probabilidade. As barras representam os desvios padrões das médias.

\section{Concentrações de prolina}

As concentrações de prolina aumentaram de $3,98 \mu \mathrm{mol}$ de Pro/g MS para $8,91 \mu \mathrm{mol}$ de Pro/g MS nas raízes das plantas submetidas à deficiência hídrica, representando um aumento de $119 \%$. Nas folhas das plantas submetidas à deficiência hídrica foi observado um aumento de 2,99 $\mu \mathrm{mol}$ de Pro/g. MS para 6,56 $\mu \mathrm{mol}$ de Pro/g. MS, representando um aumento de 124,06\%.

Esse aumento da prolina possivelmente foi decorrente da diminuição do conteúdo relativo de água (Figura 1), pois quando sob período de baixa disponibilidade de água, a planta recorre ao ajustamento osmótico como mecanismo de proteção (MONTEIRO et al., 2014); Esse comportamento, permite a manutenção 
de vida por um determinado tempo enquanto espera que o ambiente volte a ter condições de vida adequadas. O ajuste osmótico é um mecanismo fisiológico eficaz para que a planta permaneça túrgida quando sob condições de baixo potencial hídrico no solo (MARIJUAN \& BOSCH, 2013), auxilia na manutenção da abertura estomática e no funcionamento do aparelho fotossintético, permitindo assim, que este opere mesmo em condições de baixo potencial hídrico (HAYAT et al., 2012). Este mecanismo é correlacionado ao grau de resistência da cultura, uma vez que constitui uma estratégia adaptativa aos efeitos causados pelos estresses. Tal proteção é eficaz quando considerados pequenos períodos de tempo, ou seja, quando as condições não tardam a se normalizar (MONTEIRO et al., 2014).

O aumento da concentração de prolina durante a deficiência hídrica ocorreu, pois durante a seca, plantas superiores acumulam, através do ajuste osmótico, açúcares, ácidos orgânicos, íons e aminoácidos, no citosol ou no vacúolo, para diminuir o potencial osmótico e, consequentemente, manter o potencial hídrico e o turgor das células próximo ao nível ótimo; assim como preservar a integridade de proteínas, enzimas e membranas (ASHRAF et al., 2011; MARIJUAN \& BOSCH, 2013).

Em plantas superiores, o acúmulo de prolina pode estar relacionado à síntese "de novo" (BRITO et al., 2008), ou seja, maior atividade das enzimas envolvidas na biossíntese de prolina como a ornitina aminotransferase e pirrolina-5-carboxilase redutase (MADAN et al., 1995) e à diminuição do catabolismo (inibição da enzima de degradação, a prolina oxidase). A baixa utilização de prolina na síntese proteica durante 0 estresse e do aumento na proteólise, também podem contribuir para 0 acúmulo (BRITO et al., 2008).

A prolina atua na proteção da membrana plasmática, como fonte de carbono e nitrogênio (HEMAPRABHA et al., 2013). Sob deficiência hídrica, a membrana celular sofre alterações em canais de transporte ativados por pressão, desestruturação da conformação ou da justaposição de proteínas embebidas nas membranas celulares, além de modificações da continuidade entre a parede celular e a membrana celular (NEPOMUCENO et al., 2001).

O aumento do teor de prolina pode ser também para à atuação desse aminoácido, em plantas sob estresse, na formação de uma superfície de solvatação, uma vez que a mesma é hidrofílica e solúvel em soluções aquosas. Segundo BARTELS \& SUNKAR (2005), as moléculas provenientes de ajuste osmótico que apresentam caráter hidrofílico solúvel, no caso a prolina, são capazes de produzir uma superfície de solvatação, capturando moléculas de água para posterior utilização. Esse mecanismo ocorre pela atração entre a região eletricamente positiva da água pela parte elétrica negativa dos íons e a parte elétrica negativa da água pela parte elétrica positiva dos íons formados pelo ajuste osmótico, ficando-os envolvidos por moléculas de água. Esses solutos apresentam também função osmoprotetora contra subprodutos tóxicos do metabolismo, resultantes do estresse hídrico (MONTEIRO et al., 2014).

Segundo HEMAPRABHA et al., (2013), após o período de estresse, a prolina acumulada, pode ser usada como fonte de energia, com a redistribuição de nitrogênio e carbono, para a recuperação de atividades fisiológicas na planta. Resultados semelhantes foram encontrados por SILVA (2013) em plantas de pinhão manso submetidas à seca severa, as quais apresentaram um acúmulo de prolina de 3,35 e 2,92 mmol/g MS para os genótipos CNPAE 183 e 191, respectivamente. 


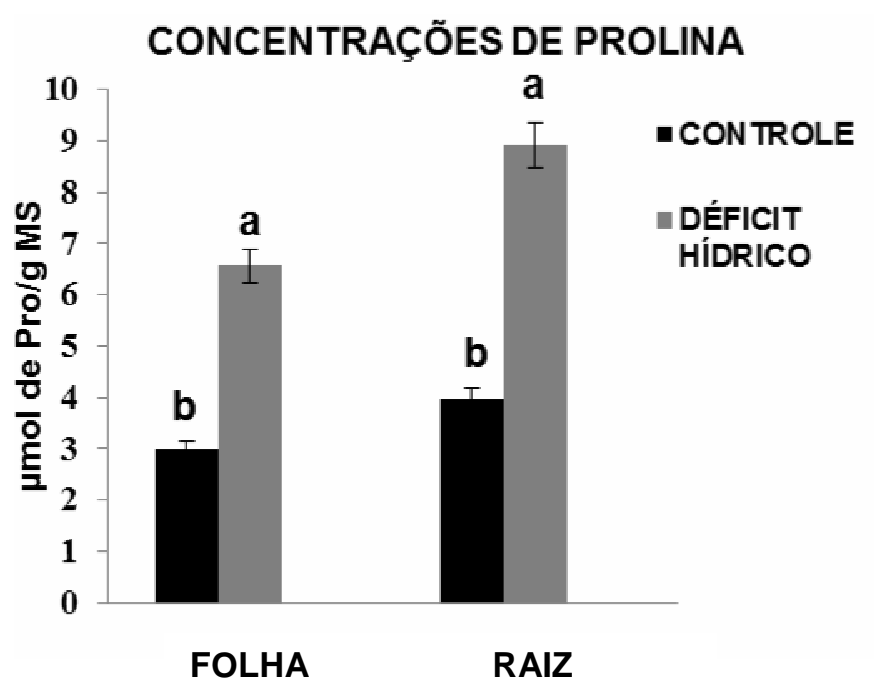

FIGURA 7 Concentrações de prolina em raízes e folhas de plantas jovens de noni (Morinda citrifolia) submetidas à deficiência hídrica durante 10 dias. As letras diferentes mostram diferença estatística, comparada pelo teste Tukey ao nível de $5 \%$ de probabilidade. As barras representam os desvios padrões das médias.

\section{CONCLUSÕES}

Os resultados obtidos permitiram concluir que as plantas de noni submetidas à deficiência hídrica apresentaram ajustamento osmótico à condição imposta de estresse, uma vez que as concentrações de aminoácidos aumentaram e as de proteínas diminuíram. Por outro lado, as plantas de noni apresentaram maiores concentrações de amônio, o que viabilizou maior absorção de nitrogênio por esta via, mantendo assim as atividades metabólicas.

\section{REFERÊNCIAS}

ALVES, G. A. R.; SANTOS, F. B. G. dos.; LOBATO A. K. da S.; YUEN TAN D. K; OLIVEIRA NETO, C. F. de; COSTA, R. C. L. da, ÁVILA, F. W.; MARQUES, D. J; GALATE, R. S. dos. Water relations, nitrogen compounds and enzyme activities in leaf and root of young Yellow Lapacho (Tabebuia serratifolia) plants subjected to flooding. Plant Omics Journal, v. 5, n. 3, p. 216-222, 2012.

ANDRADE NETTO, J. F. Atividade das enzimas redutase do nitrato e glutamina sintetase em cafeeiro arábica. Dissertação de mestrado em Agronomia - Área de Concentração em Fitotecnia. Universidade de São Paulo, Piracicaba. 2005.

ASHRAF, M.; AKRAM, N. A.; ALQURAINY, F.; FOOLAD, M. R. Drought tolerance: roles of organic osmolytes, growth regulators, and mineral nutrients. Advances in Agronomy, v.111, p.249-296, 2011.

BARTELS, D.; SUNKAR, R. Drought and salt tolerance in plants. Critical Reviews 
in Plant Sciences, v.24, p.23-58, 2005.

BATES, L. S.; WALDREN, R. P.; TEARE, I. D. Rapid determination of free proline for water-stress studies. Short communication. Plant and Soil. v.39, p.205-207, 1973.

BOtReL, M. A., PEREIRA, A. V., FREITAS, V. P., XAVIER, D. F. Potencial forrageiro de nove clones de capim elefante. Revista Brasileira de Zootecnia, $v$. 29, p.334-340, 2000.

BRADFORD, M. M. A rapid and sensitive method for the quantitation of microgram quantities of protein utilizing the principle of protein-dye binding. Anal. Biochem. v. 72, p.248-254,1976.

BRITO, L.K.F.L. de; SILVEIRA, J.A.G.; LIMA, L.L.F. de; TIMÓTEO, A.R. de S.; CHAGAS, R.M.; MACEDO, C.E.C. de. Alterações no perfil de frações nitrogenadas em calos de cana-de-açúcar induzidas por déficit hídrico. Pesquisa Agropecuária Brasileira, v.43, p.683-690, 2008.

CAMARGOS, L. S. Análise das alterações no metabolismo de nitrogênio em Canavalia ensiformes (L) em resposta a variações na concentração de nitrato fornecido. Dissertação de mestrado em Ciências. Área de concentração - Fisiologia e bioquímica de plantas. ESALQ/USP. 2002.

CARVALHO, P. A. Metabolismos do nitrogênio e antioxidante em plantas jovens de seringueira (Hevea $\mathrm{sp}$ ) submetidas à baixa disponibilidade de oxigênio na presença de nitrato e/ou amônio. Dissertação de mestrado em Agronomia. Área de concentração - Fisiologia Vegetal. UFLA, 2012.

CATALDO, D. A.; HAROON, S. L. E; YOUGS, V. L. Rapid colorimetric determination of nitrate in plant tissue by nitration of salicylic acid. Commum Soil Science Plant Analyse, v.6, n.1, p.71-80, 1975.

CHA-UM, S.; NHUNG, N. T. H.; KIRDMANEE, C. Effect of mannitol and salt induced iso-osmotic stress on proline accumulation, photosynthetic abilities and growth characters of rice cultivars (Oryza sativa L. spp indica). Pakistan Journal of Botany, v.42, p.927-941, 2010.

COOPER, M.; ROSA, D. J.; MEDEIROS, J. C.; OLIVEIRA, T. C. de; TOMA, R. S., JUHÁSZ, C. E. D. Hydro-physical characterization of soils under tropical semideciduous forest. Scientia Agricola, v.69, n.2, p.152-159, 2012.

CRUZ, J. L. Efeitos de níveis de nitrato sobre o metabolismo do nitrogênio, assimilação do $\mathrm{CO} 2$ e fluorescência da clorofila a em mandioca. 87f. Tese de doutorado - fisiologia vegetal. Universidade Federal de Viçosa, 2001.

CVIKROVÁ, M.; GEMPERLOVÁ, L.; MARTINCOVÁ, O.; VANKOVÁ, R. Effect of drought and combined drought and heat stress on polyamine metabolism in proline ENCICLOPÉDIA BIOSFERA, Centro Científico Conhecer - Goiânia, v.11 n.22; p.102 2015 
over producing tobacco plants. Plant Physiology and Biochemistry, v.73, p.7-15, 2013.

FERREIRA, V. M.; MAGALHÃES, P. C.; DURÃE, F. O. M.; OlIVEIRA, L. E. M. de.; PURCIN, A. A. C. Metabolismo do nitrogênio associado à deficiência hídrica e sua recuperação em genótipos de milho. Ciência Rural, Santa Maria, v.32, n.1, p.13-17, 2002.

FILIPPOU, P.; BOUCHAGIER, P.; SKOTTI, E.; FOTOPOULOS, V. Proline and reactive oxygen/nitrogen species metabolism is involved in the tolerant response of the invasive plant species Ailanthus altissima to drought and salinity. Environmental and Experimental Botany, v.97, p.1-10, 2014.

FREITAS, J. M. N. de. Comportamento ecofisiológico e bioquímico de plantas jovens de acapú (Vouacapoua amaricana Aubl.) submetida á deficiência hídrica. 2014. 100f. Tese (Doutorado em Ciências Agrárias). Universidade Federal Rural da Amazônia, Belém.

HAGEMAN, R. H. G.; HUCKLESBY, D. P. Nitrate reductase from higher plants. In: METHODS IN ENZIMOLOGY, 17 A, p.497-505. 1949.

HAYAT, S.; HAYAT, Q., ALYEMENI, M. N., WANI, A. S.; PICHTEL, J.; AHMAD, A. Role of proline under changing environments: A review Plant Sigaling \& Behavior, v.7, n.11, p.1456-1466, 2012.

HEMAPRABHA, G.; SWAPANA, S.; LAVANYA, D. L.; SAJITHA, B.; VENKATARAMANA, S. Evaluation of Drought Tolerance Potential of Elite Genotypes and Progenies of Sugarcane (Saccharum sp. hybrids). Sugar Tech, v.15, n.1, p.916, 2013.

KAISER W. M.; HUBER S. C. Pos-translation regulation of nitrate reductase: mechanism, physiological relevance and environmental triggers. Journal of Experimental Botany, v.52, n.363, p.1981-1989, 2001.

Lambers, H.; Chapin, F. S.; Pons, T. L. (2008) Plant Physiological Ecology. Springer, New York, USA, 604p.

MADAN, S.; NAINAWATEE, H. S.; JAIN, R. K.; CHOWDHURY, J. B. Proline and proline metabolizing enzymes in in-vitro selected $\mathrm{NaCl}$-tolerant Brassica juncea $\mathrm{L}$. under salt stress. Annals of Botany, v.76, p.51-57, 1995.

MARAGHNI M.; GORAI M.; NEFFATI M. The Influence of Water-Deficit Stress on Growth, Water Relations and Solute Accumulation in Wild Jujube (Ziziphus lotus).Journal of Ornamental and Horticultural Plants, v.1, n.2, p.63-72, 2011.

MARIJUAN, M. P.;BOSCH, S. M.Ecophysiologyofinvasiveplants: osmotic adjustment and antioxidants. Trends in Plant Science, v.18, p.660-666, 2013. 
MELO, E. F. Modificações ecofisiológicas, bioquímicas e anatômicas em cafeeiro progênie Siriema sob deficiência hídrica. Dissertação de Mestrado em Agronomia, área de concentração - Fisiologia Vegetal. UFLA - MG. 2008.

MONTEIRO, J. G.; CRUZ, F. J. R.; NARDIN, M. B.; SANTOS, D. M. M. dos. Crescimento e conteúdo de prolina em plântulas de guandu submetidas a estresse osmótico e à putrescina exógena. Pesquisa Agropecuária Brasileira, v.49, n.1, p.18-25, 2014.

NEPOMUCENO, A. L.; NEUMAIER, N; FARIAS, J. R. B.; OYA, T. Tolerância à seca em plantas. Biotecnologia, Ciência \& Desenvolvimento, n.23, p.12-18, 2001.

NEMANI, R. R.; KEELING, C. D.; HASHIMOTO, H.; JOLLY, W. M.; PIPER, S. C.; TUCKER, C. J.; MYNENI, R. B.; RUNNING, S. W. Climate-driven increases in global terrestrial net primary production from 1982 to 1999. Science, 300:1560-1563. (2003).

OLIVEIRA NETO, C.F; Crescimento, produtividade, comportamento fisiológico e bioquímico de plantas de sorgo (Sorghum bicolor [L.] moench) submetidas ao déficit hídrico. 114p. (Dissertação de mestrado em Agronomia) - Universidade Federal Rural da Amazônia, 2008.

OLIVEIRA, L. M. de; SILVA, J. N. da; COELHO, C. C. R.; NEVES, M. G.; SILVA, R. T. L. da; OLIVEIRA NETO, C. F. de. Pigmentos fotossintetizantes, aminoácidos e proteínas em plantas jovens de graviola submetida ao déficit hídrico. Agroecossistema, v.5, n.1, p.39-44, 2013.

PACHECO, A. C.; CAMARGO, P. R.; SOUZA, C. G. M. Deficiência hídrica e aplicação de $A B A$ nas trocas gasosas e no acúmulo de flavonoides em calêndula (Calendula officinalis L.). Acta Scientiarum. Agronomy, v.33, n.2, p.275-28, 2011.

PAIXÃO, C. L. da; JESUS, D. S. de; COSTA, P. D.; PEREIRA, P. P. A.; NETO, A. D. A. Caracterização fisiológica e bioquímica de genótipos de girassol com tolerância diferenciada ao estresse hídrico. Enciclopédia Biosfera, v.10, n.19; p.2011-2022, 2014.

PAULA, M. T.; SANTOS FILHO, B. G. dos; CORDEIRO,Y. E. M.; CONDE, R. A.; NEVES, P. A. P. F. G. Ecofisiologia do mogno brasileiro (Swietenia macrophylla King) em sistemas agroflorestais no município de santa Bárbara-PA. Enciclopédia Biosfera, v.9, n.16, p.813-824, 2013.

PEOPLES, M. B., FAIZAH, A. W., REAKASEM, B. E HERRIDGE, D. F. Methods for evaluating nitrogen fixation by nodulated legumes in the field. Australian Centre for International Agricultural Research Canberra, p.76, 1989.

POMPELLI, M. F.; BARATA-LUÍS, R.; VITORINO, H. S.; GONCALVES, E. R.; ROLIM, E. V.; SANTOS, M. G.; ALMEIDA-CORTEZ, J. S.; FERREIRA, V. M.; LEMOS, E. E.; ENDRES, L. Photosynthesis, photoprotection and antioxidant activity 
of purging nut under drought deficit and recovery. Biomass Bioenergy, p.1-9, 2010.

SALISBURY, F. B; ROSS, C. W. Fisiologia das plantas. Cengage learning. 4.ed, São Paulo. 774p, 2012.

SANTOS, R. R.; ALMEIDA, A. A. da S.; ALMEIDA, J. C. R. Atividade da redutase do nitrato em mudas de açaizeiro adubadas com nitrogênio e potássio. Revista biociência, v.18, p.13-17, 2012.

SAS INSTITUTE. SAS/STAT User's Guid: version 6.12, SAS Institute, Cary, NC. 1996.

SCHWART, G. Manejo sustentável de florestas secundárias: espécies potenciais no Nordeste do Pará, Brasil. Amazônia: Ciência; Desenvolvimento, v.3, n.5, p.125147, 2007.

SEPEHR, M. F.; HORBANLI, M. G.; AMINI, F. The effect of water stress on nitrate reductase activity and Nitrogen and phosphorus contents in cuminum cyminum I. Pakistan Journal of Botany, v.44, n.3, p.899-903, 2012.

SHARMA, P.; DUBEY, R. S. Modulation of nitrate reductase activity in rice seedlings under aluminium toxicity and water stress: role of osmolytes as enzyme protectant. Journal of Plant Physiology, v.162, n.8, p.854-864, 2005.

SILVA, L. D. da. Alterações fisiológicas e bioquímicas em genótipos de Jatropha curcas I. submetidos ao déficit hídrico. 114p. Dissertação de mestrado em Produção Vegetal, da Universidade Estadual de Santa Cruz - UESC, 2013.

SILVA, L. R. da; MEDEIROS, P. V. Q. de; LEITE, G. A.; SILVA, K. J. P.; MENDONÇA, V.; SILVA, G. G. da. Caracterização do fruto de Morinda citrifolia L. (noni). Revista Cubana de Plantas Medicinales, v.17, n.1, p.93-100, 2012.

SILVA, S. M.; OLIVEIRA, L. J.; FARIA, F.P.; REIS, E. F.; CARNEIRO, M. A. C.; SILVA, S. M. Atividade da enzima nitrato redutase em milho cultivado sob diferentes níveis de adubação nitrogenada e potássica, Ciência Rural, v.41, n.11, p.19311937, 2011.

SILVA, V. A.; ANTUNES, W. C.; GUIMARÃES, B. L. S.; PAIVA, M. C.; SILVA, V. de F.; FERRÃO, M. A. G.; DaMATTA, F. M.; LOUREIRO, M. E. Resposta fisiológica de clone de café Conilon sensível à deficiência hídrica enxertado em porta-enxerto tolerante. Pesquisa Agropecuária Brasileira, v.45, n.5, p.457-464, 2010.

SLAVIK, B. Methods of studying plant water relations. New York, Springer-Verlag. 449p, 1974.

SOUSA, C. C. M.; PEDROSA, E. M. R.; ROLIM, M. M.; OLIVEIRA FILHO, R. A.; SOUZA, M. A. L. M; PEREIRA FILHO, J. V. Crescimento e respostas enzimáticas do feijoeiro caupi sob estresse hídrico e nematoide de galhas. Revista Brasileira de ENCICLOPÉDIA BIOSFERA, Centro Científico Conhecer - Goiânia, v.11 n.22; p.105 2015 
Engenharia Agrícola e Ambiental, v.19, n.2, p.113-118, 2015.

SOUZA, L. C. de; SIQUEIRA, J. A. M.; SILVA, J. L. de S.; SILVA, J. N. da; COELHO, C. C. R.; NEVES, M. G.; OlIVEIRA NETO, C. F. de; LOBATO, A. K. da S. Compostos nitrogenados, proteínas e aminoácidos em milho sob diferentes níveis de Sílica e deficiência hídrica. Revista Brasileira de Milho e Sorgo, v.13, n.2, p.117128, 2014.

SZÁBADOS, L.; KOVACS, H.; ZILBERSTEIN, A.; BOUCHEREAU, A. Plants in extreme environments: importance of protective compounds in stress tolerance. Advances in Botanical Research, v.57, p.105-150, 2011.

TURKAN, I. Plant Responses to Drought and Salinity Stress: Developments in PostGenomic Era. In Advances in Botanical Research. v.57, p.105-150, 2011.

WEATHERBURN, M. W. Phenol hipochlorite reaction for determination of ammonia. Analytical Chemistry. v. 39, p.971-974, 1967. 